\title{
Risk factors associated with postpartum depression in the Saudi population
}

\author{
This article was published in the following Dove Press journal: \\ Neuropsychiatric Disease and Treatment \\ 17 February 2014 \\ Number of times this article has been viewed
}

\author{
Abeer A Alharbi' \\ Hamza Mohammad \\ Abdulghani ${ }^{2}$ \\ 'Department of Family and \\ Community Medicine, ${ }^{2}$ Department \\ of Medical Education, College of \\ Medicine, King Saud University, \\ Riyadh, Saudi Arabia
}

Introduction: Postpartum depression (PPD) is one of the major psychological disorders worldwide that affects both mother and child. The aim of this study was to correlate the risk of PPD with obstetric and demographic variables in Saudi females.

Materials and methods: Data were collected by interviewing females 8-12 weeks postpartum. PPD symptoms were defined as present when subjects had an Edinburgh Postnatal Depression Scale score of 10 or higher. Variables included in this study were age, education, occupation, parity, baby's sex, pregnancy period, delivery type, hemoglobin level, anemia, and iron pills taken during pregnancy.

Results: Of the 352 postpartum females, the prevalence of PPD symptom risk was 117 (33.2\%). Among the PPD symptomatic females, 66 (39.8\%) had low hemoglobin levels, and 45 (40.5\%) females were anemic during pregnancy $(P \leq 0.05)$. These results suggest that early postpartum anemia, indicated by low hemoglobin level, is a significant risk factor for PPD (adjusted odds ratio $1.70,95 \%$ confidence interval $1.05-2.74 ; P=0.03)$. Other variables, including age, parity, education, occupation, and delivery type, were not significantly correlated $(P=0.15-0.95)$, but marginally indicative of the risk of depressive symptoms.

Conclusion: Low hemoglobin level and anemia during pregnancy were risk factors for PPD in Saudi females. Many other factors may be considered risk factors, such as age, occupation, and parity. Anemic women need more attention and to be checked regarding their PPD, and treated if necessary.

Keywords: postpartum depression, hemoglobin level, anemia, EPDS

\section{Introduction}

Postpartum depression (PPD) is the most common psychological health problem among women, affecting $10 \%-15 \%$ worldwide. ${ }^{1}$ It is characterized by tearfulness, despondency, emotional lability, feelings of guilt, loss of appetite, suicidal ideation, sleep disturbances, poor concentration and memory, fatigue, and irritability, as well as feelings of inadequacy. ${ }^{2,3}$ PPD can develop at any time during the first postpartum year. ${ }^{4}$ Usually, 50\%-80\% females experience mood disturbance during the first week, which peaks at day 5, and may be fully resolved within 10-14 days postpartum. ${ }^{5}$ Mood disturbance can prevail after the third week of child delivery and/or up to 1 year and can evolve into PPD, which may affect both the mother's and the child's health. 6,7 Full-blown PPD affects the entire family and creates an economic burden on the family as well as on the public health system. ${ }^{8,9}$ In most cases, high depressive risk was reported during the first 3-4 months postpartum. ${ }^{10,11}$ Hence the screening of PPD is extremely important and could be performed regularly after 4-6 weeks postpartum. ${ }^{11,12}$
Correspondence: Hamza Mohammad Abdulghani

Assessment and Evaluation Unit, Department of Medical Education College of Medicine, King Saud University, PO Box 230I55, Riyadh II32I, Saudi Arabia Fax +966 I 4699174 Email hamzaab@ksu.edu.sa submit your manuscript $\mid$ www.dovepress.com

Dovepress

http://dx.doi.org// 0.2147/NDT.S57556
Neuropsychiatric Disease and Treatment 2014:10 311-316

(c) (i) (5) 2014 Alharbi and Abdulghani. This work is published by Dove Medical Press Limited, and licensed under Creative Commons Attribution - Non Commercial (unported, v3.0) License. The full terms of the License are available at http://creativecommons.org/licenses/by-n/3.0/. Non-commercial uses of the work are permitted without any further permission from Dove Medical Press Limited, provided the work is properly attributed. Permissions beyond the scope of the License are administered by Dove Medical Press Limited. Information on
how to request permission may be found at: http://www.dovepress.com/permissions.php 
The prevention of PPD may not be completely possible, although health professionals can help in recognizing and reducing key risk factors.

The most consistently reported risk factors are an early history of depression, history of psychiatric illness, depression during pregnancy, lack of social support, and recent life stresses. ${ }^{2,13-15}$ In addition, some risk factors are only seen in Eastern communities, such as the delivery of a female infant and grand multiparity. ${ }^{16,17}$

Nutritional deficiency has also been associated with depression in the postpartum population, including that in omega-3 fatty acids, zinc, and iron. ${ }^{18,19}$ Iron deficiency is the most prevalent nutrient deficiency in almost all childbearing women in the world. ${ }^{20}$ Postpartum iron deficiency results in common postpartum anemia caused by excessive blood loss during child delivery. ${ }^{21}$ Several studies have reported that anemia due to iron deficiency was associated with increased symptoms of PPD. ${ }^{22,23}$ However, controversial associations have also reported between maternal iron status, low hemoglobin $(\mathrm{Hb})$ level, maternal anemia, and PPD. ${ }^{24}$ In our literature search, we did not find any studies that reported the risk factors of PPD in the Saudi population. Hence we decided to determine the prevalence of PPD and its associated risk factor(s) in demographic and obstetric variables, including anemia among patients using obstetric and "well-baby" clinic services of two Saudi hospitals.

\section{Materials and methods \\ Place and duration of study}

The study was conducted at the King Khalid University Hospital (KKUH) and Riyadh Military Hospital (RMH) (AlWazarat Primary Health Care Centers), Riyadh, Kingdom of Saudi Arabia, from April 2013 to May 2013 (6 weeks).

\section{Study design and data-collection tool}

The design of the study was observational case-control and retrospective. Depressive symptoms were assessed in Saudi women who had had their babies delivered in KKUH or RMH at 8-12 weeks postpartum and among those attending primary health care centers for their baby's vaccination. Exclusion criteria included those who had a history of postpartum blood transfusion, early puerperium in postpartum hemorrhage and/or were known to have any previous psychiatric illness.

The Arabic-language version of the Edinburgh Postnatal Depression Scale (EPDS) was used to study depressive symptomatology. The EPDS is a ten-item self-report scale validated and widely used to screen for PPD. ${ }^{25}$ The researchers gave instructions to the mother and made sure the mother understood the questions before filling out the form. The researcher also helped, if the mother requested, to read the questions and/or explain them to her. Similar to previous studies, participants who scored 10 or higher on the EPDS were considered as possible PPD cases, and those who scored less than 10 were considered normal and therefore controls..$^{23,26}$

All of the requirements for this study were formally explained to the women in their native language. If they agreed to participate, they were asked to sign the consent form.

\section{Data-collection methods}

The research questionnaire contains 22 closed-ended questions in the Arabic language. The questionnaire is divided into three parts: the first part deals with sociodemographic variables, which include age, education level, and occupation; the second part contains obstetric history variables and past psychiatric history of the participants.

The third part of the questionnaire contains the predesigned self-administered EPDS. The EPDS is a reliable and valid instrument that has been used in research as well as primary clinical care to screen people with depressive symptomatology. ${ }^{27,28} \mathrm{Hb}$ level, anemic condition, and ironsupplement recommendations were recorded from the study participants' postnatal medical records, and anemia was defined as $\mathrm{Hb}$ level $<11 \mathrm{~g} / \mathrm{dL}^{29}$

\section{Sample size}

We assumed an unequal sample size of PPD cases (EPDS score $\geq 10$ ) and controls (EPDS score $<10$ ), (total 352, PPD cases 117 and controls 235), with an odds ratio (OR) of 2.0, at the $5 \%$ level of significance, with $80 \%$ study power and $5 \%$ expected dropout. ${ }^{30,31}$

\section{Statistical analysis}

Descriptive statistics were used for summarizing the study and outcome variables. The $\chi^{2}$ test and ORs with $95 \%$ confidence intervals (CIs) were used for observation and quantifying the association between different variables. Multivariate binary logistic regression was used to identify the independent associated factors of PPD. $P \leq 0.05$ was considered significant.

\section{Ethical considerations}

The study protocol was approved by the Local Committee of the Post-graduate Saudi Board of the central province. Approval for conducting the study was obtained from the Institutional Review Board of KKUH. The objectives of the study were explained to the participants, and their consent 
was considered a prerequisite for enrollment in the study. Confidentiality was assured through the anonymity of the questionnaire. All collected data were kept confidential and used only for study purposes.

\section{Results}

A total of 352 postpartum females who completed the demographic and obstetric variables section and the EPDS questionnaire were included in this study. Out of the 352 postpartum females, 204 (58\%) females attended KKUH and 148 (42\%) females attended RMH for baby care. Distribution of the Hb levels and PPD symptoms of the participants is presented in Table 1. Participants' age ranged from 19 to 47 years; mean age was 29.92 years (standard deviation \pm 5.7 ). Of the total participants, 207 (58.8\%) females belonged to the age-group 25-34 years, whereas $81(23 \%)$ females were aged more than 35 years. The females who participated in the study included housewives (239, 67.9\%), those employed outside the home (82, 23.3\%), those with a university education $(196,52.3 \%)$, and those with a secondary education $(104,29.5 \%)$. Most of the females had full-term pregnancy (>37 weeks; 338, 96\%) and had normal vaginal deliveries $(269,76.4 \%)$. Those who delivered male babies in their last delivery numbered $185(52.6 \%)$, primipara $115(32.7 \%)$, parity of two to three 121 (34.4\%), and more than four babies $116(33.0 \%)$.

The EPDS was divided into two (dichotomous) categories. Of the 352 mothers, 117 (33.2\%) had depressive symptoms (EPDS score $\geq 10$ ), and 235 (66.8\%) did not have depressive symptoms (EPDS scores $<10$ ). Of the 117 postpartum females with depressive symptoms, 45 (30.5\%) attended $\mathrm{RMH}$, whereas $72(61.5 \%)$ attended KKUH during pregnancy as well as for baby care. In univariate modeling, age,

Table I Distribution of hemoglobin $(\mathrm{Hb})$ levels and postpartum depression (PPD) symptoms of Saudi females in two hospitals

\begin{tabular}{ll}
\hline Baseline characteristic & $\mathbf{n}(\%)$ \\
\hline Low Hb level & $166(47.2)$ \\
Anemia & $1 \mathrm{II}(3 \mathrm{I} .53)$ \\
PPD symptoms & $117(33.2)$ \\
Attending KKUH & $204(58)$ \\
Anemia & $60(29.4)$ \\
Low Hb level & $110(53.9)$ \\
PPD symptoms & $72(35.3)$ \\
Attending RML & $148(42)$ \\
Anemia & $5 \mathrm{I}(34.5)$ \\
Low Hb level & $56(37.8)$ \\
PPD symptoms & $45(30.4)$ \\
\hline
\end{tabular}

Abbreviations: KKUH, King Khalid University Hospital; RML, Riyadh Military Hospital. education, working status, and parity were not found to be statistically significant predictors of discordant scores ( $P=0.22-0.77$ ) (Table 2). However, comparatively, the risk of PPD symptoms was slightly more in the low-age group $(37.5 \%<25$ years, OR 1.37, CI 0.76-2.46) and in the high-age group (37.0\% $\geq 35$ year; OR 1.02, CI 0.52-2.00). In addition, the risk of PPD symptoms was also slightly more in females who were employed outside the home $(36.6 \%$, OR 1.29 , CI 0.76-2.18), and engaged in continuing education (41.9\%, OR 1.61, CI 0.75-3.46). Result also showed an insignificant risk of PPD symptoms among those who delivered their child by cesarean $(34.9 \%$, OR 1.10 , CI $0.66-1.85)$ and had more than four children (35.3\%, OR 1.20, CI 0.69-2.07).

Out of the 352 postpartum females, normal $\mathrm{Hb}$ levels ( $\geq 11 \mathrm{~g} / \mathrm{dL}$ ) were found in 186 (52.8\%), whereas low $\mathrm{Hb}$ levels $(<11 \mathrm{~g} / \mathrm{dL})$ were detected in $166(47.2 \%)$. The mean $\mathrm{Hb}$ level was $10.98 \mathrm{~g} / \mathrm{dL}$ (standard deviation \pm 1.49 ). Out of the 166 low-Hb females, 56 (33.7\%) attended RMH and $110(66.3 \%)$ attended KKUH for their delivery. A total of $111(31.53 \%)$ females noticed the presence of anemia during pregnancy, with 51 (45.9\%) of them attending RMH and $60(54.1 \%)$ attending KKUH during pregnancy. Postpartum $\mathrm{Hb}$ levels were significantly correlated with females who had anemia during pregnancy $(P<0.005)$. However, no significant

Table 2 Distribution of sociodemographic characteristic and its association with postpartum depression (PPD) in Saudi postpartum females $(n=352)$

\begin{tabular}{|c|c|c|c|c|}
\hline Variables & $\begin{array}{l}\text { Participants } \\
\text { (\%) }\end{array}$ & $\begin{array}{l}\text { PPD } \\
\text { symptoms (\%) } \\
\text { EPDS } \geq 10\end{array}$ & OR $(95 \% \mathrm{CI})$ & $P$ \\
\hline \multicolumn{5}{|l|}{ Age, years } \\
\hline $25-34$ & $207(58.8)$ & 63/207 (30.4) & 1.00 & \\
\hline $35+$ & $81(23.0)$ & $30 / 81(37.0)$ & $1.34(0.78-2.30)$ & 0.28 \\
\hline$<25$ & $64(18.2)$ & $24 / 64(37.5)$ & $1.37(0.76-2.46)$ & 0.29 \\
\hline \multicolumn{5}{|l|}{ Education } \\
\hline Primary & $18(5.1)$ & $4 / 18(22.2)$ & 1.00 & \\
\hline Secondary & $104(29.5)$ & $37 / 104$ (35.6) & $1.93(0.59-6.30)$ & 0.27 \\
\hline Intermediate & $34(9.7)$ & I2/34 (35.3) & I.9I (0.5I-7.II) & 0.33 \\
\hline $\begin{array}{l}\text { University } \\
\text { and above }\end{array}$ & $196(55.7)$ & $64 / 196(32.7)$ & $1.70(0.54-5.36)$ & 0.36 \\
\hline \multicolumn{5}{|c|}{ Working status } \\
\hline Housewife & $239(67.9)$ & $74 / 239(31.0)$ & 1.00 & \\
\hline $\begin{array}{l}\text { Working } \\
\text { outside }\end{array}$ & $82(23.3)$ & $30 / 82(36.6)$ & $1.29(0.76-2.18)$ & 0.34 \\
\hline Student & $31(8.8)$ & $|3 / 3|(4 \mid .9)$ & $1.61(0.75-3.46)$ & 0.22 \\
\hline \multicolumn{5}{|l|}{ Parity } \\
\hline Primipara & II 5 (32.7) & $36 / 115$ (3I.3) & 1.00 & \\
\hline $2-3$ & I2I (34.4) & $40 / 121$ (33.I) & I.08 (0.63-I.87) & 0.77 \\
\hline $4+$ & $116(32.9)$ & $4 \mathrm{I} / 116(35.3)$ & $1.20(0.69-2.07)$ & 0.51 \\
\hline
\end{tabular}

Abbreviations: EPDS, Edinburgh Postnatal Depression Scale; OR, odds ratio; $\mathrm{Cl}$, confidence interval. 
correlation was found between postpartum $\mathrm{Hb}$ level and iron pills taken either regularly, irregularly, or never during the pregnancy period ( $P=0.338$ ). One of the important findings was a significant correlation between low postpartum $\mathrm{Hb}$ levels and having a high-risk score of PPD $(P=0.015)$ (Table 3$)$. Of the 117 females who scored $\geq 10$ on the EPDS, $66(56.4 \%)$ had low postpartum Hb levels, and 51 (43.6\%) had normal postpartum $\mathrm{Hb}$ levels (OR 1.75, CI 1.12-2.73). In addition, a proportion of females who had anemia during pregnancy had a significant risk of PPD symptoms $(P<0.049)$. We also found that very few females $(n=8)$ who had not taken iron pills during their pregnancy had a high risk of PPD symptoms (50\%) compared to those who had taken iron pills regularly (OR 2.04, CI 0.74-5.69). By using multivariate logistic regression analysis, it was observed that $\mathrm{Hb}$ levels $<11.0$ were independently associated with PPD symptoms by adjusting other variables in the model (Table 3 ).

\section{Discussion}

A number of studies have focused on PPD in women, especially on how the mother's depressive disorder can affect the infant's emotional, social, and cognitive development. ${ }^{32}$ In developed countries, health care professionals regularly screen for PPD in order to take appropriate care of motherand-child health. ${ }^{33,34}$ Our study was conducted to determine the risk of PPD and its associated factors in Saudi females. The average prevalence of PPD symptoms in the present study was higher than worldwide PPD values. The increased rate of PPD symptoms in this study is not surprising, as a review study reported a very wide range of prevalence. This is due to cross-cultural factors and a diversity of different social factors. ${ }^{35}$ Some studies have reported poor mental health, depression, anxiety, and psychiatric disorders in wives of polygamous husbands. ${ }^{36,37}$ An important finding in this study were the significant correlations between anemia during pregnancy and postpartum $\mathrm{Hb}$ levels and between low $\mathrm{Hb}$ levels and risk of PPD symptoms. In addition, a proportion of females who were anemic during pregnancy also showed significant correlation with risk of PPD. Earlier international studies also suggested that early postpartum anemia, as indicated by low $\mathrm{Hb}$ concentration, is a significant risk factor for PPD. ${ }^{22,38,39}$ Low Hb levels cause weakness, faintness, painful perineal sutures, and tingling of the extremities. ${ }^{20}$ Several studies have also demonstrated the negative effect of anemia on self-reported quality of life, contributing to depression in the mother. ${ }^{40,41}$ The link between low $\mathrm{Hb}$ levels and high EPDS scores is an important finding in the present study. The cause of relatively low Hb levels in the Saudi population is unclear, although the most common cause of reduced $\mathrm{Hb}$ in healthy adults is iron deficiency. ${ }^{42}$ Iron deficiency was reported in about $50 \%$ of women of reproductive age. ${ }^{30}$ Stewart ${ }^{42}$ reported that iron deficiency contributes to PPD. In the current study, females who had not taken iron pills during pregnancy had high EPDS scores. Iron supplementation to

Table 3 Obstetric variables, EPDS score, and postpartum depression (PPD) in Saudi postpartum females ( $\mathrm{n}=352$ )

\begin{tabular}{|c|c|c|c|c|}
\hline Variables & $\begin{array}{l}\text { Participants } \\
\text { (\%) }\end{array}$ & $\begin{array}{l}\text { PPD symptoms (\%) } \\
\text { EPDS } \geq 10\end{array}$ & Crude OR $(95 \% \mathrm{Cl})$ & Adjusted OR (95\% CI) \\
\hline \multicolumn{5}{|l|}{ Hemoglobin } \\
\hline $\mathrm{II}+$ & $186(52.8)$ & $51 / / 86(24.7)$ & 1.00 & 1.00 \\
\hline$<11$ & $166(47.2)$ & $66 / 166(39.8)$ & $1.75(1.12-2.73)^{*}$ & $1.70(1.05-2.74)^{* *}$ \\
\hline \multicolumn{5}{|l|}{ Pregnancy period } \\
\hline Full term ( $>37$ weeks) & $338(96.0)$ & I I I/338 (32.8) & 1.00 & 1.00 \\
\hline Preterm & $14(4.0)$ & $6 / 14(42.9)$ & $1.53(0.5 \mathrm{I}-4.53)$ & $1.57(0.52-4.76)$ \\
\hline \multicolumn{5}{|l|}{ Delivery type } \\
\hline Normal & $269(76.4)$ & $88 / 269(32.7)$ & 1.00 & 1.00 \\
\hline Cesarean & $83(23.6)$ & 29/83 (34.9) & $1.10(0.66-1.85)$ & $0.96(0.56-1.64)$ \\
\hline \multicolumn{5}{|l|}{ Sex of child } \\
\hline Male & $185(52.6)$ & $61 / / 85(33.0)$ & 1.00 & 1.00 \\
\hline Female & $167(47.4)$ & $56 / 167(33.5)$ & $1.03(0.66-1.60)$ & $1.04(0.66-1.64)$ \\
\hline \multicolumn{5}{|c|}{ Anemia during pregnancy } \\
\hline No & $24 I(68.5)$ & $72 / 24 \mid(29.8)$ & 1.00 & 1.00 \\
\hline Yes & III (3I.5) & $45 / I I I(40.5)$ & $1.60(1.00-2.56)^{*}$ & $\mathrm{I} .44(0.89-2.34)^{* *}$ \\
\hline \multicolumn{5}{|c|}{ Iron pills given during pregnancy } \\
\hline Regular & $201(57.1)$ & $66 / 201(32.8)$ & 1.00 & 1.00 \\
\hline Irregular & $135(38.4)$ & $43 / \mid 35$ (3I.8) & $0.96(0.60-1.52)$ & $0.95(0.59-1.53)$ \\
\hline No & $16(4.5)$ & $8 / 16(50)$ & $2.14(0.74-5.69)$ & I.88 (0.66-5.34) \\
\hline
\end{tabular}

Notes: *Statistically significant $(P=0.01 ; P=0.04)$; **tatistically significant $(P=0.03 ; P=0.05)$.

Abbreviations: EPDS, Edinburgh Postnatal Depression Scale; OR, odds ratio; Cl, confidence interval. 
prevent PPD could be possible in women who are anemic during pregnancy or soon after giving birth. ${ }^{22}$

Postpartum females who were most likely to have low $\mathrm{Hb}$ levels and have an abnormal delivery (cesarean) were significantly correlated $(P=0.005)$. In addition, a proportion of females $(34.7 \%)$ who were identified as anemic during pregnancy had complications relatively more often during delivery (including cesarean) compared to a nonanemic mothers. Therefore, this result may be consistent with an earlier study that showed that caesarean delivery leads to increased risk of PPD. ${ }^{43}$

The demographic variables included in this study revealed that relatively younger and older female groups were associated with higher risk of PPD, which is similar to previous studies, which stated that advanced and young age are the risk factors for PPD. ${ }^{44,45}$ This case-control study has also revealed that there was low risk of PPD among housewives compared to those who were working away from their homes. However, in contrast to our finding, other studies have reported an excess risk of PPD among housewives..$^{46,47}$ Our study did not find maternal level of education as a risk factor for PPD, which is consistent with the finding of another study, ${ }^{48}$ but differs from some other reports. ${ }^{47,48}$ No differences were observed regarding risk of PPD with regard to the sex of the child, which is in line with some other studies. ${ }^{49,50}$

\section{Limitations}

The current study is case-control based on observational data which may prove an association between low $\mathrm{Hb}$ level and PPD, but do not demonstrate causation. We used only the EPDS screening test, whereas multiple test confirmation by structured or semistructured interview is needed. In the present study, $\mathrm{Hb}$ levels were the only predictor of anemia, so we cannot be sure whether low hemoglobin levels were due to iron deficiency or any other disorder.

\section{Conclusion}

This study showed a relatively high prevalence of PPD symptoms. Early detection of risk factors for PPD may help clinicians in early intervention and management. In the present study, we concluded that low $\mathrm{Hb}$ levels and anemia during pregnancy were risk factors for PPD in our study subjects. Many other factors that may be considered risk factors are age, occupation, and parity. Therefore, efforts should be made to provide intervention for depression by providing support at home. We further advise that a psychiatrist and a social worker should attend a postnatal care unit to advise mothers who may be at risk of developing not only PPD but also other psychiatric disorders. We would also like to recommend that further studies are needed in the Saudi community to investigate further some of the risk factors that were found to be associated with PPD.

\section{Acknowledgments}

The authors would like to thank all participants who took part in this study. We also thank Dr Shaffi Ahmad Shaikh for helping with statistical analysis, and Dr Mohammad Irshad and Professor Riaz Quiraishi for reviewing and editing the whole manuscript.

This work was funded by the College of Medicine Research Centre, Deanship of Scientific Research, King Saud University, Riyadh, Saudi Arabia.

\section{Disclosure}

The authors report no conflicts of interest in this work.

\section{References}

1. Vigod SN, Villegas L, Dennis CL, Ross LE. Prevalence and risk factors for postpartum depression among women with preterm and low-birthweight infants: a systematic review. BJOG. 2010;117(5):540-550.

2. Robertson E, Grace S, Wallington T, Stewart DE. Antenatal risk factors for postpartum depression: a synthesis of recent literature. Gen Hosp Psychiatry. 2004;26(4):289-295.

3. McGarry J, Kim H, Sheng X, Egger M, Baksh L. Postpartum depression and help-seeking behavior. J Midwifery Womens Health. 2009;54(1): 50-56.

4. Chaudron LH. Postpartum depression: what pediatricians need to know. Pediatr Rev. 2003;24(5):154-161.

5. Thurgood S, Avery DM, Williamson L. Postpartum depression (PPD). Am J Clin Med. 2009;6(2):17-22.

6. Sanjuan J, Martin-Santos R, Garcia-Esteve L, et al. Mood changes after delivery: role of the serotonin transporter gene. Br J Psychiatry. 2008;193(5):383-388.

7. Wisner KL, Chambers C, Sit DK. Postpartum depression: a major public health problem. JAMA. 2006;296(21):2616-2618.

8. Steiner M, Dunn E, Born L. Hormones and mood: from menarche to menopause and beyond. J Affect Disord. 2003;74(1):67-83.

9. Burt VK, Quezada V. Mood disorders in women: focus on reproductive psychiatry in the 21st century - Motherisk update 2008. Can J Clin Pharmacol. 2009;16(1):e6-e14.

10. Verkerk GJ, Pop VJ, Van Son MJ, Van Heck GL. Prediction of depression in the postpartum period: a longitudinal follow-up study in high-risk and low-risk women. J Affect Disord. 2003;77(2):159-166.

11. Sheeder J, Kabir K, Stafford B. Screening for postpartum depression at well-child visits: is once enough during the first 6 months of life? Pediatrics. 2009;123(6):e982-e988.

12. Peindl KS, Wisner KL, Hanusa BH. Identifying depression in the first postpartum year: guidelines for office-based screening and referral. $J$ Affect Disord. 2004;80(1):37-44.

13. Wisner KL, Perel JM, Peindl KS, Hanusa BH, Piontek CM, Findling RL. Prevention of postpartum depression: a pilot randomized clinical trial. Am J Psychiatry. 2004;161(7):1290-1292.

14. O'Hara MW. Postpartum depression: what we know. J Clin Psychol. 2009;65(12):1258-1269.

15. Forty L, Jones L, Macgregor S, et al. Familiality of postpartum depression in unipolar disorder: results of a family study. $\mathrm{Am} \mathrm{J}$ Psychiatry. 2006;163(9):1549-1553. 
16. Xiea R, Hea G, Liua A, Bradwejn J, Walker M, Wen SW. Fetal gender and postpartum depression in a cohort of Chinese women. Soc Sci Med. 2007;65(4):680-684.

17. Gürel S, Gürel H. The evaluation of determinants of early postpartum low mood: the importance of parity and inter-pregnancy interval. Eur J Obstet Gynecol Reprod Biol. 2000;91(1):21-24.

18. Bloch M, Rotenberg N, Koren D, Klein E. Risk factors for early postpartum depressive symptoms. Gen Hosp Psychiatry. 2006;28: 3-8.

19. Bodnar LM, Wisner KL. Nutrition and depression: implications for improving mental health among childbearing-aged women. Biol Psychiatry. 2005;58(9):679-685.

20. Patterson AJ, Brown WJ, Roberts DC, Seldon MR. Dietary treatment of iron deficiency in women of childbearing age. Am J Clin Nutr. 2001;74(5):650-656.

21. Kavle JA, Stoltzfus RJ, Witter F, Tielsch JM, Khalfan SS, Caulfield LE. Association between anaemia during pregnancy and blood loss at and after delivery among women with vaginal births in Pemba Island, Zanzibar, Tanzania. J Health Popul Nutr. 2008;26(2):232-240.

22. Corwin EJ, Murray-Kolb LE, Beard JL. Low hemoglobin level is a risk factor for postpartum depression. J Nutr. 2003;133(12):4139-4142.

23. Albacar G, Sans T, Martín-Santos R, et al. An association between plasma ferritin concentrations measured $48 \mathrm{~h}$ after delivery and postpartum depression. J Affect Disord. 2011;131(1-3):136-142.

24. Armony-Sivan R, Shao J, Li M, et al. No relationship between maternal iron status and postpartum depression in two samples in China. J Pregnancy. 2012;2012:521431.

25. Ghubash R, Abou-Saleh MT, Daradkeh TK. The validity of the Arabic Edinburgh Postnatal Depression Scale. Soc Psychiatry Psychiatr Epidemiol. 1997;32(8):474-476.

26. Klainin P, Arthur DG. Postpartum depression in Asian cultures: a literature review. Int J Nurs Stud. 2009;46(10):1355-1373.

27. Leung BM, Kaplan BJ, Field CJ, et al. Prenatal micronutrient supplementation and postpartum depressive symptoms in a pregnancy cohort. BMC Pregnancy Childbirth. 2013;13:2.

28. Garcia-Esteve L, Ascaso C, Ojuel J, Navarro P. Validation of the Edinburgh Postnatal Depression Scale (EPDS) in Spanish mothers. J Affect Disord. 2003;75(1):71-76.

29. World Health Organization. Worldwide Prevalence of Anaemia 1993-2005: WHO Global Database on Anaemia. Geneva: WHO; 2008.

30. Milman N. Postpartum anemia II: prevention and treatment. Ann Hematol. 2012;91(2):143-154.

31. Perfetti J, Clark R, Fillmore CM. Postpartum depression: identification, screening and treatment. WMJ. 2004;103(6):56-63.

32. Markhus MW, Skotheim S, Graff IE, et al. Low omega-3 index in pregnancy is a possible biological risk factor for postpartum depression. PLoS One. 2013;8(7):e67617.

33. Davies BR, Howells S, Jenkins M. Early detection and treatment of postnatal depression in primary care. J Adv Nurs. 2003;44(3): $248-255$.
34. Zauderer C. Postpartum depression: how childbirth educators can help break the silence. J Perinat Educ. 2009;18(2):23-31.

35. Halbreich U, Karkun S. Cross-cultural and social diversity of prevalence of postpartum depression and depressive symptoms. J Affect Disord. 2006;91(2-3):97-111.

36. Daoud N, Shoham-Vardi I, Urquia ML, O’Campo P. Polygamy and poor mental health among Arab Bedouin women: do socioeconomic position and social support matter? Ethn Health. Epub May 30, 2013.

37. Shepard LD. The impact of polygamy on women's mental health: a systematic review. Epidemiol Psychiatr Sci. 2013;(1):47-62.

38. Goshtasebi A, Alizadeh M, Gandevani SB. Association between maternal anaemia and postpartum depression in an urban sample of pregnant women in Iran. J Health Popul Nutr. 2013;31(3):398-402.

39. Parhizkar A. The relation between anemia and postpartum depression in pregnant women who referred to health and medical centers of Sanandaj in 2011-2012. Life Sci J. 2013;10(7s):308-312.

40. Beard JL, Hendricks MK, Perez EM, et al. Maternal iron deficiency anemia affects postpartum emotions and cognition. J Nutr. 2005;135(2): 267-272.

41. Haider BA, Olofin I, Wang M, Spiegelman D, Ezzati M, Fawzi WW. Anaemia, prenatal iron use, and risk of adverse pregnancy outcomes: systematic review and meta-analysis. BMJ. 2013;346:f3443.

42. Stewart RC. Maternal depression and infant growth - a review of recent evidence. Matern Child Nutr. 2007;3(2):94-107.

43. Boyce PM, ToddAC. Increased risk of postnatal depression after emergency caesarean section. Med J Australas. 1992;157(3):172-174.

44. Bjerke SE, Vangen S, Nordhagen R, Yiterdahl T, Magnus P, Stray Pedersen B. Postpartum depression among Pakistani women in Norway: prevalence and risk factors. J Matern Fetal Neonatal Med. 2008;21(12): 889-894.

45. Wolff A, De-Andraca I, Lozoff B. Maternal depression in three Latin American samples. Soc Psychiatry Psychiatr Epidemiol. 2002;37(4): 169-176.

46. Lee DT, Yip AS, Leung TY, Chung TK. Identifying women at risk of postnatal depression: prospective longitudinal study. Hong Kong Med J. 2000;6(4):349-354.

47. Goker A, Yanikkerem E, Demet MM, Dikayak S, Yildirim Y, Koyuncu FM. Postpartum depression: is mode of delivery a risk factor? ISRN Obstet Gynecol. 2012;2012:616759.

48. Saleh El-S, El-Bahei W, El-Hadidy MA, Zayed A. Predictors of postpartum depression in a sample of Egyptian women. Neuro Psychiatr Dis Treat. 2013;9:15-24.

49. Rahman A, Iqbal Z, Harrington R. Life events, social support, and depression in childbirth: perspectives from a rural community in the developing world. Psychol Med. 2003;33(7):1161-1167.

50. Sylvén SM, Papadopoulos FC, Mpazakidis V, Ekselius L, SundströmPoromaa I, Skalkidou A. Newborn gender as a predictor of postpartum mood disturbances in a sample of Swedish women. Arch Womens Ment Health. 2011;14(3):195-201.
Neuropsychiatric Disease and Treatment

\section{Publish your work in this journal}

Neuropsychiatric Disease and Treatment is an international, peerreviewed journal of clinical therapeutics and pharmacology focusing on concise rapid reporting of clinical or pre-clinical studies on a range of neuropsychiatric and neurological disorders. This journal is indexed on PubMed Central, the 'PsycINFO' database and CAS.
Dovepress

The manuscript management system is completely online and includes a very quick and fair peer-review system, which is all easy to use. Visit http://www.dovepress.com/testimonials.php to read real quotes from published authors. 